\title{
Valuing health technology - habilitating and prosthetic strategies in personal health systems
}

\author{
Alexander Peine*, Ellen H.M. Moors \\ Innovation Studies, Copernicus Institute of Sustainable Development, Utrecht University, P.O. Box 80115, 3508 TC Utrecht, The Netherlands
}

\section{A R T I C L E I N F O}

\section{Article history:}

Received 22 July 2013

Received in revised form 13 August 2014

Accepted 14 August 2014

Available online 3 October 2014

\section{Keywords:}

Health technology

Aging

Personal health systems

Generification

Configurational technology

\begin{abstract}
A B S T R A C T
This paper explores the tensions in ICT-driven personal health systems innovation and the impact of these tensions on valuing health innovation for older people. We regard personal health systems (PHS) as configurational technologies and information infrastructures that need to strike a balance between offering standardized health and care packages on the one hand, and providing options for localization and personalization on the other. We use insights from Science and Technology Studies (STS) to conceptualize the configurational dynamics of PHS innovation and emphasize 'generification work' as an important arena for the development, assessment and adoption of personal health innovations. We explore two research and development projects of PHS service-robot platforms and build on Callon's concepts of 'prosthesis' and 'habilitation' to identify two ideal-typical generification strategies in the projects. A prosthetic generification strategy positions the robot as part of a socio-technical agencement that configures older persons into disciplined agency, while a habilitating strategy speaks to them as active actors in the innovation process. We demonstrate how the designers in both projects were often unconsciously led into a prosthetic strategy despite initial intentions to the contrary. We explain this by mechanisms of personalization, needs capturing and othering. However, elements of habilitating strategies were also present, although in a less articulated form. We identify these elements and argue that in aging societies, health innovations need to pursue prosthesis and habilitation simultaneously. We conclude our paper with implications for innovation policy and health technology assessment.
\end{abstract}

(c) 2014 Elsevier Inc. All rights reserved.

\section{Introduction}

Demographic aging is one of the drivers behind the trend toward more personalized and patient-centered health and care systems: health policymakers have identified the prevention, (self-)management and treatment of chronic rather than acute diseases as a major challenge (Nolte and McKee, 2008). As a consequence, health technology interventions are increasingly positioned within the wider context of supporting active and healthy aging and independent living (Cabrera and Malanowski, 2009). The arenas in which health technologies

\footnotetext{
* Corresponding author. Tel.: +31 30253 2782; fax: +31 302532746.

E-mail address: a.peine@uu.nl (A. Peine).
}

are created and adopted thus shift from those associated with primary and secondary care to wider cross-sectoral settings including domestic environments, home care services, ICT companies, construction firms, etc. (Huch, 2010). The recent attention to TeleCare and eHealth is only one part of this development (Mort et al., 2012; Oudshoorn, 2011; Pols and Willems, 2011). Probably more interesting developments concern full-fledged personal health systems (PHS) in which medical functions move into homes and private lives, where they merge with other non-medical devices and information infrastructures (Codagnone, 2009; Schartinger et al., 2012; Abadie et al., 2011; Peine et al., 2015-this issue). These developments suggest that aging societies need to re-think the creation, evaluation, procurement and adoption of health innovation that shifts health and care practices from hospitals 
to homes, and merges treatment and care with prevention and consumption (Peine et al., 2014).

In Western countries, health technology and ICT are increasingly positioned as a solution to the problems usually associated with aging (Oudshoorn, 2011; Roberts and Mort, 2009) - such as the increased prevalence of cognitive impairments in older age groups, the increasing risk of falls and accompanying severe injuries, or the higher prevalence of diabetes, elevated blood pressure and heart diseases. As other contributions in this special issue, especially those of Aceros et al. (2015-this issue), López Gómez (2015-this issue) and Pritchard and Brittain (2015-this issue), show: such solutions for supporting older persons in their homes neither leave the identity of the home nor existing practices of care unchanged. ICT-based health or care interventions engage technology more closely with the lives and practices of older persons, their caregivers and the community environment, but they hardly do so as otherwise neutral interventions (Oudshoorn, 2011). On the contrary, they redefine boundaries (between health and disease, between citizens and patients, between what is considered active and what is not), they limit or enable (sometimes in unexpected ways) agency in one way or the other, and they define new socio-technical arrangements in which responsibilities, actions and interactions are re-distributed among existing and new stakeholders involved with health and care.

In this paper, we strive to link insights from these contributions to recent discussions about the "personal health technology revolution' (Dishman, 2012). To this end, we interrogate how designers imagine the use and domestication of technology. Building further on the work of Pollock, Williams and others in Science and Technology Studies (STS) (Pollock et al., 2007; Pollock and Williams, 2008; Johannessen and Ellingsen, 2009; Williams and Pollock, 2012), we introduce 'generification work' as an important arena in which designers interweave such images with broader ideas about the pathways of technology into society. To this end, we present an empirical analysis of two research and development projects on PHS service robot platforms. The paper proceeds as follows: Section 2 introduces our theoretical background and defines the tension between localization and generification as a key challenge in PHS innovation. Section 3 provides the methodological background and case selection rationale for our empirical analysis. In Section 4, we present the two research projects in more detail, and provide insights about how the designers articulate 'their' technology together with the values it should provide in the lives of users. In Section 5, we trace how such perceptions were transformed when designers tried to make them generic, i.e., translate them into generic design features. Using Callon's distinction between 'prosthesis' and 'habilitation' (Callon, 2008), we identify two ideal-typical generification strategies, and elaborate how they position older persons either as objects of technological interventions or as agents of technological change. The concluding Section 6 explores policy implications for innovation policy and health technology assessment.

\section{Aging and personal health systems}

Our point of departure is the recent attention to ICT solutions to support aging well, which has led to considerable funding at European and national levels (see the introduction of this special issue (Peine et al., 2015-this issue), also (Cabrera and Malanowski, 2009). In this context, ICT-driven health technologies have emerged that focus on the monitoring, prevention and management of disease outside of the institutional regimes of primary and secondary care. In aging societies, health care is moving into homes and communities (Willems, 2010) and ICT is expected to play a central role in this process. It integrates health and care technologies more closely with everyday lives and the practices of patients, citizens, caregivers, family members and communities (Dishman, 2012; Asveld et al., 2009; Mort et al., 2009). Older persons are a primary target group in this development. It is thus interesting to explore in more detail how they are imagined and involved in innovation processes of ICT-driven health and care technologies.

\subsection{Personal health systems as configurational technology}

ICT systems for collecting, monitoring and managing health-related data and providing interventions in home environments have recently been termed personal health systems (PHS) (Codagnone, 2009; Schartinger et al., 2012; Abadie et al., 2011). This term emphasizes the expectation that ICT-based health technologies that operate in domestic and community environments will allow for a (more or less) individualized integration with the existing practices and routines of its users. Moreover, a common promise is that PHS will provide for a seamless integration of health and care ICT with existing information infrastructures (Abadie et al., 2011), thus contributing to more age-friendly environments at household, community and regional levels (WHO, 2007). While PHS cover a broad variety of innovations, ${ }^{1}$ they share the broad idea that health technology in domestic environments needs to be 'localized' to the specific needs, practices and situations of people and their social contexts. In complementing earlier notions like TeleCare or eHealth, the term PHS highlights that ICT-supported health technologies have to find a space within both existing technological infrastructures (interfaces like tablets or TV sets, standards and protocols, available bandwidth, data security, etc.) and existing practices in homes and communities.

Conceptually, therefore, the notion of PHS emphasizes that many ICT-driven health technologies resemble what the recent STS literature terms configurational technologies or information infrastructures (Fleck, 1993; Peine, 2009; Pollock and Williams, 2010). That is, PHS include a range of (more or less) standardized components whose specific set-up depends on local contingencies, including embodied practices, routines and existing technological infrastructures. A simple example for the configurational nature of PHS is a serious gaming solution for cognitive training (see Zelinski and Reyes, 2009). Such a game can operate as a stand-alone application in an existing domestic ICT infrastructure. It can also operate as part of a more formal rehabilitation trajectory involving data exchange with health or care professionals (making use of domestic as well as regional health or care ICT infrastructure), or it can be used to facilitate social gaming and contests between users (again making use of

\footnotetext{
${ }^{1}$ A good overview is provided at http://www.phsforesight.eu.
} 
domestic as well as community ICT infrastructures). The point is that the software package that constitutes the game remains the same across all these use scenarios; its specific embedding in existing information infrastructures and local practices, however, differs considerably. From an innovation perspective, this is challenging insofar as it illustrates how PHS need to strike a fine balance between offering standardized packages on the one hand, and providing options for localization and personalization on the other (Pollock et al., 2007; Peine, 2007; Stewart and Williams, 2005).

In the remainder of this section, we use insights from STS and innovation studies to conceptualize the configurational dynamics of PHS innovation. In doing so, we provide means for policymakers and innovation managers to grasp more adequately the move of health technologies from hospitals into private homes and communities. Regarding the latter, previous STS studies, including the abovementioned from this special issue, have drawn attention to the complex localization work that is necessary to make health technology work in private homes. Through such localization efforts, patients, caregivers, family members, installers, ICT companies, artifacts, skills and so forth "produce a specific practice [...] of care" (Oudshoorn, 2011). TeleCare services, for instance, come into being in local processes of alignment, tinkering and domestication - processes that in turn reshape existing networks, practices and responsibilities in home care (Mort et al., 2012; Pols and Willems, 2011; Pols and Moser, 2009; Sanchez-Criado et al., 2014; Schillmeier and Domenech, 2010; Mol et al., 2010). Localization studies have shown that 'ICT solutions' - as PHS are often labeled in policy documents and research programs (Cenderello et al., 2013) - are anything but solutions to pre-existing problems. Rather, their implementation alters existing definitions of what relevant problems are, and who should take responsibility for them (Oudshoorn, 2011).

Our paper links with these studies and seconds the claim that the implementation of health technology needs to be understood in relation to the specific networks of (human and non-human) actors to which it gives rise (Willems, 2010; Mort et al., 2013; Mol et al., 2010). But we strive to take this insight into the realm of PHS innovation processes. That is, while we share the above authors' criticism toward a simplistic positioning of PHS as 'ICT solutions,' we also believe that the reasons and sources of this positioning deserve attention in their own right. Indeed, technology designers, researchers and developers in research institutes and private companies are often well aware of the real world intricacies and socio-technical dynamics of putting complex technologies to use (Peine et al., 2014; Peine and Neven, 2011) - often in contrast to what is revealed in publicly available documents about PHS innovation. It is thus puzzling how rich representations of technology use in context are sidelined by simplified representations of technology as a clear-cut intervention or solution during innovation processes or research projects.

We argue that to better understand PHS innovation, it is necessary to complement the above-cited localization studies with an analysis of 'generification work' - i.e., the work necessary to export specific solutions from their context to make them generic in the form of predefined packages that can be produced and marketed (Pollock et al., 2007; Pollock and Williams, 2008; Williams and Pollock, 2012). Generification work highlights that ideas of technology as generic solutions emerge from attempts to process insights about local context into generic designs. Quite often, such attempts have been remarkably successful in reconciling openness to local specifics with generic requirements. Enterprise resource planning software like SAP is the paradigmatic example in the literature (Pollock and Williams, 2008). Overall, however, our conceptual and empirical insights of generification processes have remained relatively scarce. Studying them requires moving "beyond the single site implementation study" (Williams and Pollock, 2012), and zooming in on various spaces and arenas through which local and generic knowledge packages migrate in innovation processes (Pollock et al., 2007; Peine, 2007; Peine and Herrmann, 2012).

\subsection{Personalizing personal health systems}

Recent work on health innovation has started to address this challenging agenda of following the pathways of health technology over time and across space (Lehoux, 2006; Faulkner, 2009; Hyysalo, 2010). Our paper contributes to this emerging body of research and zooms in on the localization vs. generification challenge in innovation processes of PHS. Indeed, this challenge has been widely recognized as being pivotal, as the following quote from a recent EU study about business models in "ICT for aging well" illustrates:

In all cases [of viable PHS businesses], the successful involvement of the public sector is strongly dependent on there being a forward-looking, public investment driven approach and policies to support public spending. This is linked to the need for clear and demonstrable savings on the funder and provider sides (the business case), as well as user benefits in terms of convenience and quality of life (the social case) in addition to any user cost savings. (Cenderello et al., 2013)

In this quote, the requirement of providing economic value for suppliers is coupled seamlessly with the simultaneous requirement of addressing highly contingent, locallybounded values such as convenience or quality of life. What this statement conflates into one 'need' pertains to entities of quite different scales: The business case, on the one hand, refers to an effect of the wider dissemination of an abstract 'object' - the ICT solutions, in this instance. The social case, by contrast, marks attributes that emerges when the object is localized thus enacting specific networks or practice. These two aspects are not independent, but the statement glosses over their inherent differences in scale and location. The report is nevertheless quick to suggest a solution and continues that "it is important that the financing strategy is targeted at developing highly flexible products and services which can fit a variety of situations and conditions" (Cenderello et al., 2013). This illustrates the importance of the generification vs. localization challenge for PHS innovation: as a generic business, PHS need to demonstrate economic value and improvement across national and European health and care systems; but as specific manifestations, their value arises through localization into different "situations and conditions." 
EU policymakers and other stakeholders thus recognize ${ }^{2}$ that the move of health and care technology into homes and communities requires a 'localized' and 'personalized' approach to implementation - somehow. Tensions and contradictions between generification and localization only emerge on closer inspection and are not acknowledged as such. So far, it is still unclear how demonstrating the generic value of PHS in relation to existing health and care systems and ICT sectors can be reconciled with managing the diverse socio-technical arrangements through which PHS are 'valued' locally (see McLaughlin et al., 1999). At this point, the contribution of STS and innovation studies outlined above becomes clear: It lies in its capacity to open the black box of localization vs. generification, and to disentangle the various forms of values, responsibilities and agencies that are so effortlessly merged in typical EU policy documents relating to 'ICT and aging well.'

In what follows, we complement the above-discussed TeleCare implementation studies with an analysis of the generification work upstream of a PHS innovation process. In so doing, we focus on an important arena of health innovation that has so far been widely neglected in the literature (Lehoux, 2006). That is, we analyze the practices of technology designers in the PHS domain. Our analysis focuses on two aspects: First, we interrogate how the designers perceived the localization of their technology, and thus tap into the imageries they employed when envisioning 'their' technology in context. Secondly, we analyze the steps and ideas the designers implemented to make these imageries generic in the form of design features, user representations, and (envisioned) implementation efforts.

\section{Case selection and methodology}

In what follows, we present the results of two case studies that we have conducted in the context of a larger research project on technology researchers and designers, and how they imagine older technology users and their interactions with technology. The larger study investigated four R\&D research projects on service robot platforms and smart living environments. A total of 18 semi-structured, qualitative interviews with key research personnel in these projects was held. Moreover, we analyzed public project deliverables and information published on websites. The interviews themselves were based on a qualitative-inductive approach, which implies that data analysis started as soon as the first interviews were completed, and the interview questions evolved together with the emerging conceptual landscape. ${ }^{3}$

For this paper, we have revisited the original data of the two robot service platform projects. In line with the idea of theoretical sampling, we chose the robot cases on the basis of their theoretical relevance rather than representativeness (Flick, 2009; Eisenhardt and Graebner, 2007). Indeed, among the more sophisticated PHS technologies that receive dedicated attention on research agendas are robotic services and

\footnotetext{
${ }^{2}$ In fact, the above statement seems to be typical in characterizing how EUlevel policymakers and other actors perceive the key challenge of PHS innovation. This is also exemplified, for instance, by the fact that the current H2020 program has a dedicated theme for 'Personalizing health and care,' which, by and large, describes the key challenge for research and innovation of health technology along the lines suggested by the statement above.

3 The study design, results and methodological underpinnings about this original study have been published in (Meulenbroek, 2011).
}

applications (Codagnone, 2009; Abadie et al., 2011). PHS robots are both a vividly debated topic in relation to serving older persons (Flandorfer, 2012; Kohlbacher and Hang, 2011), and an example of a health innovation that enters the domestic environment of users: an underlying expectation is that service robots can provide medical and care services, while at the same time providing a sense of companionship and support that transcends immediate medical or treatment functions (Neven, 2010). ${ }^{4}$ Against this background, the two robot cases are excellent examples of PHS in an early stage of development. As such, the original data from these cases allowed us to study how researchers and designers address and frame the generification vs. localization challenge as they position the robot in relation to future use and innovation pathways. The material from the two robot cases also proved to be a good empirical basis, as the original research question - how do researchers and designers imagine older technology users and their use practices? - also seemed to unravel a key tension that, based on a first cursory revisiting of the data, permeated the interview statements: the technology researchers and designers apparently struggled with the contradictory ideas of their robot serving older persons as patients in care markets, and as consumers in consumer markets. This tension seemed to imply more interesting underlying questions about how the designers and researchers in these projects framed the value of 'their' robot in relation to the lives of older persons, the regulatory regimes (perceived to be) important, and the envisioned innovation pathways into society.

In order to grasp this tension more systematically, we reanalyzed the eight interview transcripts from the robot cases as well as the published project deliverables. These interviews were held between February and May 2011, either face-to-face or via telephone. All interviews took between 30 and 100 minutes and were audiotaped and then transcribed verbatim into either Dutch or English (depending on the interview language). The project deliverables were project reports describing different phases in the development process, such as the outcome and methods of certain user involvement methods, service scenarios, and pilot tests, as well as descriptions and demonstration videos of technological solutions. We have re-analyzed eleven such project deliverables, which were also used in the original study.

For the present study, we have imported all the original data into QSR-Nvivo 10, and re-analyzed it using a selective, interpretive coding scheme during April and May 2014. In this re-analysis, we followed a theory-elaborating approach (Vaughan, 1992, 2004), ${ }^{5}$ and used the above ideas of generification and localization as sensitizing concepts to focus the analysis (Blumer, 1954; Bowen, 2006). We assigned a running number to each analyzed interview transcript and

\footnotetext{
${ }^{4}$ An example for a companionship robot is the famous Paro - essentially a robotic seal that should provide the kind of companionship normally associated with living animals (Kohlbacher and Hang, 2011). See http://www.parorobots. com.

${ }^{5}$ Theory elaboration of analogical theorizing is an approach inspired by Grounded Theory (Corbin and Strauss, 2008), but specifically tailored for the elaboration and strengthening of theoretical concepts derived from other research sites. That is, it follows standard Grounded Theory procedures including coding, constant comparison and concept development, yet it allows for theoretical concepts to enter the analysis right away (Eisenhardt and Graebner, 2007; Vaughan, 1992, 2004; Eisenhardt, 1989).
} 
document; these numbers are provided as reference where we quote interviewees or documents in the analysis below.

Some of the interviewees were concerned with confidentiality as both projects also included confidential deliverables and results of potential commercial interest. We thus keep the research projects as well as project participants anonymous. For this reason, it is not possible to provide illustrations of the envisioned technologies beyond a generic description, nor to refer to project websites or project deliverables directly. For the sake of simplicity, our subsequent analysis refers to designers when we talk about project interviewees; we use the term designer in a broad sense, including all actors involved with technology research, development and design. Finally, the interviews were taken at a single point in time, yet covered different phases of the service robot projects (see Section 4.1). We need to stress that when we talk about practices and activities in different project phases, the respective insights are based on the recollections of the interviewees. We did not follow or observe the project through different phases. This approach is in line with the overall interpretivist stance (Bryman, 2006) we chose for our research, implying that we were interested in how key actors in the projects made sense of localization and generification. Moreover, analyzing interviews that covered different times and spaces allowed us to avoid the pitfalls of a detailed single-site study that tends to push attention to generification work to the sidelines (see Section 2.1).

\section{Designing PHS service robot platforms}

\subsection{Case descriptions}

The investigated projects have been funded under the EU's 7th Framework Programme Theme on 'ICT and Aging,' and their aim was to develop a robot platform to support older persons in health and wellbeing. Both projects have thus explored robots as platforms for the provision of a potentially wide and adaptable set of services in the homes of older persons. The robots serve as interactive and more or less selfreliant devices that can move freely in the homes of people. In the projects, it was envisioned that the robots would become embedded in the context of smart living environments, including different sensors for the monitoring of behavior, a range of consumer electronics, and communication with care givers, family members and friends. In short, the platforms were meant to operate seamlessly within a broader ICT and data infrastructure, including third party applications and services to support aging well at home. From a technology research perspective, the key challenge for the platforms lay in their flexibility along the spatial (free movement), interactional (interaction through speech, movements, and expressions) and informational (seamless ICT infrastructure integration) dimensions. Technologically, both platforms were challenging in terms of the underlying mechanical engineering and ICT interoperability. Nonetheless, both projects aimed at low-cost solutions that could be built, at least in principle, with off-theshelf components. The research focus in both projects, therefore, was on systems integration and configuration rather than on improving the state of the art in robotics. This implied that the projects had a strong focus on user involvement and testing, where the available state-of-the-art technology should be provided in configurations that make sense to different types of users. In both cases, the envisioned end-users were older people living at home independently. The specific contexts of use, however, were not specified in the project proposals, so that gradually defining and specifying contexts and scenarios of use remained an important aspect during the projects. The scope of both projects included the development and testing of prototypes, but not the development of marketable products or services.

The first project, with the fictitious name Nice, ${ }^{6}$ was a threeyear project. Its central goal was to improve the well-being of older persons together with their family members and friends, and to increase the efficiency of existing care systems. Accordingly, the platform was developed to include features that provide potential users with comfort and care services focusing on the areas of lifestyle and coaching, fun and entertainment, and social connectedness, including a care alarm with video conferencing and monitoring. In the Nice project, the interface design was considered to be crucial, as Nice was, above all, regarded to be a generic entry point for a broad range of different services and third party applications into the homes of older persons. During the project, a number of prototypes were developed and tested with users in various development stages with a range of methods. At the time we held the interviews, a number of focus groups had been conducted as a design input, and a Wizard of Oz test had been executed in order to evaluate a first prototype. ${ }^{7}$ For the future, living lab tests as well as trial implementations at the homes of elderly persons had also been planned, but not yet been implemented. The prototypes were low-cost but feasible solutions that used off-the-shelf technology in a non-humanoid design. That is, the prototypes moved on wheels but did not have arms and legs, as this was considered to be too sophisticated in technological terms. Nonetheless, the Nice robots strove to realize a basic resemblance with human interaction. They could move freely in a room (although they could not climb stairs), they could 'listen and see' (through a camera and microphone), and they included a screen as the basic interface that could simulate the appearance of a face or facilitate video conversations. The Nice prototypes were able to have basic spoken communication with users.

The other service robot platform project, with the fictitious name mCare, also was a three-year project that aimed at developing a social companion robot embedded in a smart living environment. Quite similarly to Nice, the mCare project explored possibilities of using the robot for the provision of a range of different features, including cognitive stimulation, health monitoring, falls detection, lifestyle and health coaching, as well as various control and communication functions. At the time the interviews were held, extensive attempts to explore user needs (including those of caregivers, family members and friends) had been conducted over a period of 5-6 months, employing methods such as observations, interviews, focus groups and cultural probes studies. From the knowledge

\footnotetext{
6 This should not be confused with the British National Institute for Health and Care Excellence also abbreviated Nice. We are grateful for one anonymous reviewer for pointing this out.

7 In a Wizard of $\mathrm{Oz}$ test, a not fully functioning version of the robot is remotely controlled by a researcher to interact with test persons.
} 
thus gathered, an expert commission, consisting of mCare researchers, end user representatives, and experts from gerontology and housing, then extracted a priority list. This list was the basic input for the design of robot prototypes. For the future, additional focus groups and trial implementations in the home of users had been planned, but not yet been implemented at the time of the interviews. Also the mCare project focused on non-humanoid prototypes that could move independently on wheels through an apartment, and it offered a basic resemblance to human interaction by means of speech and voice recognition. A distinct feature of the mCare robot was envisioned to be its ability to use input from sensors installed in a test apartment to recognize the behavioral patterns of its inhabitants. For instance, when a person would sit on the sofa for too long, or not have a telephone conversation for a while, mCare would autonomously approach the person and suggest, for better or worse, an intervention - such as engaging the person in physical exercise. mCare was, however, a pure research project, meaning that a prototype robot and smart environment were developed and tested, but no marketable products were developed.

\subsection{Turning the home into a health place}

When the designers talked about their technological work and their representations of older technology users and later life more generally, they frequently referred to a central challenge - that the robots would have a hybrid position at the intersection of medical treatment, care, and everyday life. The robots would bring health technology into the homes of people, but as such they could not maintain their identity as a health- or care-related assistive device. Rather, the designers struggled to define the robot as combining the identity of an assistive device with that of a 'life companion' that would provide meaning, entertainment, social connectedness or simply fun:

We call it lifestyle vs. care. It is about the combination. A specific care device is doomed to stand in the corner, you need it to function. But you are proud of lifestyle...'look what a beautiful thing I have'... you don't do this with a blood sugar meter or a scale. The idea is that you buy a lifestyle device that helps you as you grow older, this is the philosophy... (I1)[...] and I am working in the health division and my group is medical device technology, and we are doing research on how the home could be some health place. Nice for us is the possibility to determine how service robotics can deliver our services and how we can use the robot to perform clinical assessments in the home environment. (I3)

Turning the home into a 'health place,' indeed, was a central topic that emerged from the interviews, and this had important implications for the specific framing of health technology. In fact, it was the home environment that threw into question the whole idea of the robot as a purely assistive device that could neatly be evaluated using clinical assessments, as the same interviewee pointed out:

I think the robot could be bought in younger ages than real elderly people, because the goal of Nice is that the robot is some sort of lifestyle product that you are proud of and that you can show to your friends. (I3)

Here, the idea of the home as a 'health place' is broadened to comprise everyday situations in which the value of a technology depends on whether you can be proud of it or even brag about it. The home, therefore, was the place in which the identity of the robot as an assistive device collapsed and needed to be complemented with the fuzzier identity of a 'lifestyle product.' How lifestyle and assistance could be reconciled in design, however, remained a challenge that typified both projects.

One way of addressing this challenge was to emphasize the platform character of the robots. In the rhetoric of the designers, the robots sometimes transformed into a sort of neutral interface that would provide and seamlessly blend a broad range of conceivable services and functions - a range which in itself would not be part of the robot's generic design. Some of the designers even delegated the creation of specific configurations to the networks in which the robots would eventually operate:

[...] the services are not the goal, it is important that people accept the services; acceptance is very important. The functionality of a service is not very important for this but how a service communicates with you and how you can influence what the service does for you. [...] Look at the app store of Apple or that of Android; here you have ten- or a hundred thousand applications; we need something similar for the care market. (I1)

In this statement, the robot is not described as a closed package, with a specifically defined functionality, but as an open platform that, from the perspective of the designers, can be populated with services from elsewhere. The range of such services discussed during the interviews was broad, including falls detection, health status monitoring, communication with family, doctors and caregivers, collaborative gaming, personal tracking techniques, lifestyle management, and interface functionality for other devices in the home. But the robots themselves were imagined and built as interactive and playful devices that could adapt to a variety of circumstances, lifestyles and conditions across space and over time. The specific blend of services and functions to be offered would depend on the specific circumstances and the input of its user and his or her wider context of caregivers, medical professionals, friends and relatives.

What transpires from this struggle to position the robots as open platforms is the interesting way in which the designers also positioned the identity of future end-users somewhere in between that of a patient and that of a 'normal,' younger consumer. During the interviews, the designers meandered between these poles: Sometimes they would evoke specific conditions or diseases for which the robot could provide a solution; at the same time, they would underpin that 'their' users should not be described solely in terms of such conditions - but neither should they be seen as any other arbitrary consumer. Rather, the interviews evoked an imagery of hybrid patient-consumers that are in many ways like other consumers - displaying new acquisitions, bragging about them, and thus simply using them as part of everyday life - but struggling to incorporate emerging diseases and vulnerabilities 
into their lives. This hybrid identity is mobilized in particular when possible pathways of health technologies into homes and communities are described, as illustrated by the following statements:

Essentially, the end product becomes part of people's homes only when they really need it, but you need to prepare this. You do not want to start with the mCare technology when you desperately need it, but it is more practical if this happens a bit earlier... and for sure you want to involve people in your surroundings in this. (I5)

This statement defines a typical mCare user as a patient; yet this patient and his immediate social networks need to have the chance to become familiar with the robot before it is actually needed. In this perspective, an incentive is necessary that makes the robot attractive also if no medical need exists. The following statements demonstrate how, against this background, the designers went to great lengths in order to imagine older persons as hybrid patient-consumers:

Obviously we do have growing numbers of older people, some of whom will need to increase their level of support as they become older, but I think we also have to remember that older people still have lots of abilities and lots to offer to their local communities and society generally. [...] And technology I think has a huge role to play in doing that. (I8)[...] then you want to offer a kind of lifestyle management [...] as support and incentive to live healthier, care more about their food and exercise more. This is typical for people that are still healthy, but then you also have this range of people that are really ill, for which you really need medical devices, but in between there is another group... (I2)

These statements highlight that the patient-consumer has needs that evolve over time, and that supportive technology has to adapt to these evolving needs. The designers regularly evoked an idea of older persons that were still healthy, but also were coping with the onset of various conditions or vulnerabilities like memory loss, increased risk of falling, limited physical strength, loneliness and others. In the talks with the designers, patient-consumers appropriate the robot as a consumer technology that is fun, entertaining and conspicuous; and because they appropriate it for these reasons, they will also learn to use it in dealing with incipient conditions, or, if necessary, integrate it in more formalized treatment or care plans. The robot thus has a messy identity that combines elements of a fancy gadget and consumer device, of an empowerment tool for self-managing disease, and of a traditional medical or care device to support a well-defined treatment plan. This positioning, in turn, frequently intertwines possible pathways into the homes of people with ideas of future use. In the talks with the designers, however, it was not always clear whether the need to offer the robots on regular markets caused them to think about the user as a consumer, or whether deliberations of the robot in context led the designers to consider regular markets as the likely way of delivering the robots. In our two cases, the robots were conceived to do many things at once, and the idea of the patient-consumer did emerge when the designers tried to capture the broad potential of their platforms in relation to the lives of people.
The important theoretical point is that the designers in both projects frequently employed a sophisticated imagery of the complex realities of technology in local contexts. In fact, they seemed to be well aware that PHS devices, when entering the homes and communities of older people, needed to be objectified into the esthetic culture of the home and incorporated into everyday routines and social practice. That is, they have - in their own language - recognized that devices, whether they are medical or not, need to be domesticated and localized when entering the homes of people (Pols and Willems, 2011; Silverstone et al., 1992). In general, the designers seemed to be quite conscious about the fact that the robots were entering already complex, specific socio-technical arrangements in which technology use, health and illness would have to be negotiated further.

Against this background, however, assessing the robot's effectiveness and value, as well as defining its generic characteristics, presented a tricky task. Given the hybrid identity of the robots and their users, the values to be assessed would include fit with existing practices, the robot's identity as a companion and entertainment device, its position within social networks, interoperability with other devices, and the quality and experience of assistance and care. Evaluating the robot's value in the home environment was thus recognized as a challenge: a traditional clinical assessment and testing method, relying on 'evidence-based' procedures was deemed necessary to some extent, as the statements above suggest. But at the same time such logic was also considered to hamper the implementation of the robot because this would constrain its acceptability. Moreover, the necessary evidence was regarded as difficult to provide given the hybrid nature of the robot. Indeed, the designers were very clear that the robot would have to be attractive to older persons as 'consumers,' while at the same time its effectiveness would have to be clear to insurance companies - something which they perceived as involving a contradiction:

You mean if a health insurer will partially pay for it, or that you will get a subsidy? That is the ideal case, but then you have to prove that it [the device - A.P.] is really useful and that it saves costs, or that it is really useful/necessary for the elderly person. We position ourselves more as comfortincreasing, but that's not enough. [...] Something that is refunded through your health insurer needs to treat an illness and thus needs to be really functional and clear. All fancywork to make it more attractive... they don't want that... (I2)

Consequently, discussions of potential marketing paths meandered between the need to address consumer markets and the need to develop a device that would be viable in the evaluation schemes of public health policymakers, insurers and service providers. The imagined hybrid patient-consumers, therefore, crystallized a range of discussions in the boundary zone of consumer goods and health technology - a zone in which issues of user experience, acceptability, patient value and cost effectiveness were inherently entangled.

This boundary zone, then, is interesting because it constitutes the discursive space in which designers try to reconcile their ideas about localization with the (perceived) necessity to link their robots with markets, regulatory frameworks and the 
societal definition of the aging society more generally. When talking about this reconciliation, the designers contrasted, more or less explicitly, the complexity of the everyday use of technology with the allegedly clear-cut sphere of clinical testing and assessment. In the following sections, we take a closer look at the designers' reconciliation efforts. We show that it is during such efforts that older persons often disappear as consumers in context to re-emerge as a set of needs, as personas, or simply as patients. However, some statements suggest that more sophisticated ideas about the robots' use also survived. Sections 5.1 and 5.2, therefore, explore the generification work of the designers. That is, we put under scrutiny their ideas and attempts to define generic features of the robots, and, in that process, define responsibilities and agency in evaluating these different features.

\section{Generification strategies}

Callon has recently proposed a distinction between prosthetic and habilitation social and technology policy (Callon, 2008), see also López Gómez (2015-this issue) in this special issue). Using Barry's (2001) work on technology policy, which highlights how technology policy feeds into socio-technical arrangements that configure certain distributions and types of individual agency, Callon argues that modern network societies presuppose interactive individual agency ${ }^{8}$ Essentially, interactive individual agency emerges from a socio-technical arrangement that configures an individual in such a way that he or she has the capacity to self-manage his or her needs and lifestyle, and to develop them through the planning and execution of projects. For Callon, then, the interesting empirical question is not so much whether this "individual autonomous actor" (Callon, 2008) that permeates modern neo-liberal though is an empirical, anthropological reality. Rather, he mobilizes STS insights and invites us to explore socio-technical arrangements not only as a source of distributed action, but also as a configurator for the attribution of individual responsibility and agency. He introduces the term socio-technical agencement to refer to this twofold working of networks, which both give rise to collective action and also define the individual that is imputed with agency.

Using the metaphor of disabled persons, Callon argues that a key task for policy making, then, is to compensate "for maladjustments encountered by individuals in their professional and private lives" to "the mold of the Western neoliberal subject" (Callon, 2008; Eisenhardt and Graebner, 2007). Against this background, he defines prosthetic social policies as measures that feed into agencements that produce disciplined individual agency where "the individual is autonomous to the precise extent that [...] she follows the course of action allowed by the prostheses and inscribed in them" (Callon, 2008). The neo-liberal subject is first defined as a policy objective, and prosthetic policies are devised to discipline individuals into

\footnotetext{
${ }^{8}$ Callon uses the term 'individual agency' rather than individual actor or action to highlight that action is necessarily distributed, and that "the origins of the action $[\ldots]$ are not easily assignable" [20, p. 36]. Actions emerge from networks that include human and non-human elements. Individual agency, then, denotes a course of action that is both distributed and "is imputable to an individual since the actors themselves are led (or channeled by the arrangement) to consider the individual to be the source of the action" [20, p. 37].
}

following these earlier-defined common norms. Habilitation social policies, by contrast, are those measures that feed into agencements that produce interactive individual agency, which impute to individuals the capacity to create and explore scripts for individual action. Habilitation thus empowers individuals to contribute to the evolving mold of the neo-liberal subject itself. Both prosthesis and habilitation produce versions of the individual autonomous actor; but one is disciplined and scripted, while the other is interactive and thus able to define her own projects. "In one case, the injunction is 'Be like the others!' In the other, it is 'Be what you are!"' (Callon,2008).

In what follows, we use Callon's distinction to explore two ideal-typical strategies that the designers, often implicitly, followed and discussed for the implementation and further specification of the robot. Hence, our empirical analysis now turns to how the designers envisioned the socio-technical arrangements, or, as we should now say, agencements, that would further articulate and thus gradually realize the patientconsumers. Elements of such agencements were mobilized when designers discussed the above challenge of reconciling the need for personalization with defining the robot's generic features, value and identity (see Section 2), as well as potential pathways into existing homes and health care systems. These elements thus manifested as part of generification strategies where designers talked about how to make their robots generic (Pollock et al., 2007). We explore these elements to highlight how they feed into either a prosthetic or habilitation generification strategy. While elements of both types of strategies were intertwined in the practices and discourses of the designers, bringing them out as two distinct ideal types allows us to identify implications for PHS design and policy in the concluding Section 6 .

\subsection{Prosthetic generification}

As we have highlighted above, in both projects the designers were very well aware of the fact that their robots would have to remain open and flexible to local contingencies. While the designers espoused sophisticated ideas about the emerging patient-consumer and her needs, things became more challenging for them when these ideas had to be crystallized into concrete courses of action regarding technology design and policy. We thus looked in our data for statements that referred to such courses of action, and how they should be implemented.

From this analysis, three dominant strategies ${ }^{9}$ transpired that together describe the interlocking elements of an approach toward the realization of the patient-consumer that we might call prosthetic:

A first element is immediately related to the robot as part of a configurable environment. The designers recognized this to be a central challenge for their robots. In both cases, this challenge led the designers to perceive their robots as open platforms, rather than specific devices with a defined functionality. One strategy to deal with the challenge of generification, therefore, was to define the platform itself as a generic package, whose specific configuration would be defined by the bundle of

\footnotetext{
9 Again, we need to stress that these are strategies as envisioned by the designers. Our research did not comprise an actual analysis or observation of such strategies, as these were simply not in place yet.
} 
services that it would carry into the homes of people. Localization in this perception becomes a task in which third party service providers play a crucial role - the above statement about the app store that would be needed to fill the robot platform with services stands witness to this. Hence, one strategy to make the robot platform generic was to delegate future localization to other ICT companies and system integration services:

The platform is the hardware, the drivers and the basic software. The intelligence, computer vision, the basic principles of interaction with the users... on top of that, we defined a number of services, for instance tele presence, agenda reminders, lifestyle improvement... this is a separate work package, those services, we are still responsible for them but we do this with the other partners. (I2)

In this statement, which concerns the design and features of the robot, the interaction with the users and the configuration of service packages is formulated in rather technical terms. The platform remains open, but this in itself is framed as a challenge that needs the attention of experts. Personalization, therefore, is exported here from the local contexts of use to the broader context of technological interoperability between components and services, as well as between the partners or companies associated with them. The following statement of one of the mCare partners underpins this:

[...] in order for the mCare system to be feasible after the project, the system has been designed so that it is easily extensible. Thus, mCare relies on modular design where different functions are implemented in the independent components or component groups, which can be brought into the system. Independence of the components allows dynamic deployment of the mCare system, where the applied capabilities can be selected based on the requirements and available resources of target location and people. (I6)

Given our analysis in Section 4, we should not prematurely shrug this statement off as an example of technologists ignoring the complexities of technology in context. Rather, the specific framing of the personalization challenge emerges when local complexities need to be reconciled with design choices and the envisioned market and industry environment for the robots. Indeed, the problem of interoperability was not necessarily seen by the designers as a purely technological problem that could neatly be solved within the confines of engineering work; on the contrary, they frequently alluded to the problem of interoperability as a socio-technical problem that needs careful alignment between devices, market structures, standards, design rules, laws, procedures and epistemic styles (cf. Peine, 2008). But next to the intricacies of technology in everyday life, the socio-technical complexity of industrial production and innovation policy enters the stage when the designers 'exported' their robots from the homes and communities of people. This underlines how quickly the problem of domestication can be dislocated, especially for configurational technologies, where complex and distributed responsibilities characterize innovation processes. In this particular case, the same partners that otherwise expressed sophisticated views on their robots in the context of everyday lives disciplined the problem of personalization into a set of modular choices. They suggested a strategy in which informed choices between pre-established configurations would contextualize the robot platform. This strategy configures 'location and people' as something that can be captured and then served, not as something that evolves through interactions of people at a certain location with a specific version of the technology.

When looking at the actual practices that the designers employed to make their robots generic, a related element appears that we might call needs capturing. Indeed, when talking about the robots' ways into homes and care systems the designers frequently emphasized that is was important for the robots to obtain a meaningful and valuable position in the lives of people (which in turn was perceived to be a precondition for cost reductions in health and care systems). As a consequence, both projects employed a broad variety of procedures to involve users, and understand their interactions with and needs relating to the robots in multiple stages of the two projects (see Meulenbroek, 2011). These procedures included ethnographies, focus groups, interviews, Wizard of Oz tests, lab experiments, and test stays in living labs. In STS terms, therefore, there have been elaborate attempts to understand and come to grips with localization processes. Again, underlying problems surfaced in the practices employed to make the insights thus gained generic. In this regard, a common strategy tried to translate complex insights into concrete requirements or specific needs:

We make use of our clients that belong to our target group to try to contribute to an as-good-as-possible catalogue of requirements... what does the older person need if he is vulnerable, or gets older or is alone at home. [...] Interviews were an important way to capture the requirements of the technology we develop in mCare. We did this primarily during the first 5 or 6 months, to map soundly what our target group needs. [...] The project has a duration of three years, we are busy for a year now, and, on the basis of the obtained requirements, the technical partners start working... and this will soon be tested once more. (I5)

During generification it was thus widely regarded as crucial to translate the complex knowledge about home environments into a set of neatly defined requirements. In this particular setting, user involvement is artificially separated from design so that needs capturing became a mediatory task to make user involvement operational as a design input. Stewart et al. have previously identified this as a common design fallacy - the assumption that an ever-increasing amount of knowledge about users somewhat automatically feeds into better designs (Stewart and Williams, 2005). Our data supports this, and also demonstrates how needs capturing itself is a complex process with many potential outcomes.

The above statement illustrates how the robot projects created user involvement processes that carefully elevated the messy realities of home environments to the neatly defined sphere of user needs. In our particular case, however, the design fallacy also has a peculiar spin, and this spin has to do with the fact that older persons are seen as the main target 
group for the robots. A specific division of labor comes to the fore, as illustrated by the following statement:

[We involved] representatives of end users (e.g. gerontologists, representatives of residential homes, etc.). Please note that end-users have been invited and participated in the user requirements activities, which led to the list of all the potential functionalities and scenarios of use. The groups of experts helped us in prioritizing these requirements.(I6)

Experts were thus needed to make sense of the messy information that was obtained during various rounds of user involvement. And in this particular statement the prospective user of mCare, despite its complex identity, is positioned as somebody that exists 'out there,' and that needs careful attention by experts that would then capture the needs to be addressed.

For the argumentation in this paper, this particular form of needs capturing - that goes to great lengths in facilitating user involvement but leaves it to experts to make sense of the outcome - is interesting as it assumes that the patientconsumer, if not known already, can and should be known before the robot is freed into domestic environments. Our interview data demonstrates how this specific form of 'design paternalism' (Peine and Neven, 2011) emerges when older persons are conceived of as 'the other.' Rather than pursuing what Akrich has called the "I-methodology" (Akrich, 1995), designers in our cases imagined requirements through the lenses of difference. They pondered the needs of older persons deliberately in contrast to the needs of younger, allegedly 'normal' technology users:

So the current group of age 20 to 30 years is so used to technique [sic], they go into the market and buy something and are used to play around and it is normal for them. But this is not normal for the elderly generation, they need a bit guidance and be guided toward these techniques and I think this is a big difference.(I3)

In the mCare project, for instance, various rounds of user involvement were conducted including sophisticated methods such as ethnographic observation and cultural probes; however, when the results from these attempts were presented, they neatly appeared as 8 personas, each of which were defined through a particular psychological or physiological impairment. Normally, working with personas or use cases are common design approaches to avoid some of the pitfalls associated with needs capturing (Romero et al., 2010). But in this particular case, the combination with an implicit strategy of othering resulted in personas that focused predominantly on impairments and vulnerability - the personas emerged as patients rather than consumers. While it is not per se problematic to conceive of older persons in terms of impairments and vulnerabilities, our cases show that processes of needs capturing in combination with othering might result in images of older persons that are imbalanced by an overly strong focus on such impairments and vulnerabilities.

These three elements - personalization, needs capturing and othering - together mark a generification strategy that we might call prosthetic. That is, the patient-consumer that was so carefully defined during the talks about the robots in home environments re-emerges as a patient with a set of needs when processes of user involvement and their outcomes were discussed. Discursive elements ('target location and people') and procedures of user involvement create a socio-technical agencement for a disciplined patient-consumer. She is expected to participate in different rounds of user involvement, and provide insights about her needs, but her individual agency is limited to the extent that she contributes to carefully composing the patient-consumer as an object for design. In this strategy, users are carefully investigated, but as a set of needs rather than an agent that needs to explore what the robot could mean in his or her life:

[...] but before there were more home visits with people, where people had to fill in diaries to look at their activities of daily life... what works well, what works not so well... to understand the people better, to be able to build the personas better, in the end... (I7)

This generification strategy, we argue, gradually takes away individual agency from the elderly persons that participated in the projects, and it assembles the robot as a prosthesis that should help future users to fulfill the needs that have been composed as part of the research projects. Hence, this generification strategy positions the robot (in its various configurations) as part of a socio-technical agencement where scripts are clearly defined for both the technology and its users. Although personalization is maintained as a central element in the robot's design, the specific way of framing it disciplines the patient-consumers into the molds defined for him or her by others - such as policymakers, ICT companies, gerontologists, doctors, and technology designers.

\subsection{Habilitating generification}

The above elements of a prosthetic generification strategy strike us as pertinent, and they seem to corroborate a broader tendency to perceive older persons as passive and vulnerable users of technology (Peine and Neven, 2011). However, these elements were not the only ideas about generification that were discussed, and partially implemented, in the robot projects. On the contrary, other statements and practices underlined that more activating and open ideas about the patient-consumer were also present in the projects - ideas that resonate more explicitly with consumption as an active contribution to the innovation process (Peine et al., 2014):

[...] but the main goal here is that by using this mobile robot platform integrated with such services will actually allow the user to facilitate the connection with their own environment without having to use force to be in a specific location, in front of a screen sitting on a table. (I4)The objective of this project is to really watch if acceptance increases when you use a device, a device with which you can also do fun things... (I1)

These statements suggest that the designers, sometimes painfully, learned that robots would operate in a setting, where different kinds of users would have to be enrolled in order to define and explore the nature and potential value of a 
technology. And this is not perceived to be a matter of understanding the user better, but a matter of giving the user room to experiment with the robot in context. Therefore, these statements not only underline that the designers were aware of the complexity of localization - instead, the statements demonstrate the designers' recognition that incorporating localization requires a generification strategy that would be open to playful and creative encounters of the patientconsumer with the robots. Such instances show that the designers realized, at least to a degree, that it was not a primary concern to identify the added value of the robot beforehand, and to collect evidence of its performance against this background. Rather, the robot should be seen as an element whose 'effectiveness' would have to be explored in the wider socio-technical arrangements, including homes and communities of different types. Both the robots and its future users are positioned as agents, not as objects, in valuing the emerging configurations around the new service platforms.

During the focus groups, people said that this [the robot] needed to be just a device, but during the Wizard of $\mathrm{Oz}$ study it was really seen as a social entity, and people did talk to the device, gave it compliments and in the interviews afterwards they indicated that they really liked this... (I2)

From this statement it becomes clear that the robot actually triggered creative and unexpected reactions from its users although interactions took place in the constructed environment of a Wizard of Oz test. Reflecting on such situations, the designers acknowledged that these encounters were not only signaling that 'fun' or 'companionship' were important needs, somehow, but that they indicated a deeper need of the users to explore new roles as users of the robot. These were aspects that could not easily be translated into clear-cut requirements, however. When asked explicitly how older persons were imagined as users of mCare, one of the designers answered that this could only be done on a quite abstract and high level of aggregation:

[...] the real added value appears only when you really explore what the end-user needs, and then you are really immersed in detail, and then it is really about the interface and you have to look at a deeper level, and this needs honest attention... and you cannot say that these are the characteristics. (I7)

This statement critically questions a generification strategy that targets needs capturing. It recognizes that there is a level of underlying needs that might be too deeply grounded in the practices of everyday life, and the way the robot engages with and changes these practices. In an earlier paper, we have developed the notion of 'domesticability' to capture a design's ability to trigger and facilitate creative and playful encounters (Peine and Neven, 2011). In both of the investigated projects, some of the designers acknowledged 'domesticability,' in their own terminology, as an important design feature for the robots. At times, this became clear when they discussed viable implementation strategies. They highlighted that it is a key issue to have the robots enter private homes, so that users could get acquainted with them, tinker with them, learn about them, in other words, domesticate them. Hence, the decisive design parameters revolved around issues of domestication rather than requirements or configurations, and actual encounters with the robots are key elements in gradually defining and articulating different versions of the patient-consumer. In this perspective, the patient-consumer emerges as a playing field rather than an object, and design needs to create conditions for this playing field to emerge. A central challenge for generification work would then be to retain this degree of openness of the robot well into its diffusion, implementation and use phases.

Finally, then, we argue that these last statements and strategies, although scarcely present in the interviews, mark what we might call a habilitating generification strategy. When designers discussed the implementation of the service robots in these ways, they suggested an imagery of future users that resembles the kind of individual agency Callon has called interactive individual agency (Callon, 2008). Indeed, in these statements the designers evoked ideas of socio-technical agencements that would grant users the ability to define for themselves how to position the new device in their lives, what to do with it, and ultimately which specific balance they would give to fulfilling health, fun and entertainment functions. In a nutshell, designers sometimes acknowledged that it was important not to focus exclusively on how to fit the technology into the mold of earlier defined norms and 'needs.' Rather, they struggled to provide technology that would allow and stimulate users to explore needs, new practices and, finally, new configurations.

\section{Conclusions}

In this paper we have concentrated on an important shift that characterizes aging societies: health technology is on the move to homes and communities, where it focuses on the prevention of disease and the treatment and care for chronic conditions (Nolte and McKee, 2008). Older persons and their formal and informal networks are a key user group that drives this shift. In recent policy debates this is recognized, and scholars as well as policymakers have started to interrogate the transition of health care systems from being product and treatment driven to being patient, citizen and consumption driven (Dishman, 2012). The question then is how to frame the value of emerging health technology innovations, when they move into the homes and social networks of older persons.

To explore this question we have focused on the emerging Personal Health Systems (PHS) domain - i.e., on ICT supported health technology systems for collecting, monitoring and processing health-related data in the everyday lives of older persons. We briefly analyzed recent EU policy documents, and identified a key challenge for PHS innovation: PHS need to remain open to local contingencies, so that they can be personalized to fit specific practices and routines in homes and communities. At the same time, they have to demonstrate proven value in the context of existing health and care systems. EU policy documents identify this challenge to be pivotal, but the underlying tension between the local and generic values of PHS, and how they can be addressed simultaneously, has remained hidden and inarticulate in these documents.

STS and innovation studies can make an important contribution to come to grips with this challenge more effectively. To develop this contribution, we have built on 
recent STS work about the implementation of TeleCare technologies (Mort et al., 2012; Pols and Willems, 2011; Pols and Moser, 2009; Mol et al., 2010), and taken their insights into the domain of PHS research and design. For two illustrative PHS cases, the Nice and mCare service robot platforms, we have explored how designers arrive at certain framings of the value of their technologies when struggling to position it at the crosssection of homes and communities, on the one hand, and health and care systems, on the other. Most strikingly, we found that designers often do evoke sophisticated ideas about the complexities of localizing and domesticating technology when they were talking about the added value of their robots. Indeed, their ideas about these issues were often not so different from the sophisticated understanding developed in the implementation studies referred to above. However, matters changed considerably when the designers tried to reconcile insights about localization and domestication with the need to make their robots generic. Hence, our research has highlighted "generification work" (Pollock et al., 2007; Pollock and Williams, 2008; Johannessen and Ellingsen, 2009; Williams and Pollock, 2012) as the main route through which simplified representations of PHS, and certain ideas of their value in relation to the lives of older persons entered the two projects despite elaborate attempts to understand and consider the complexities of everyday life, and investigate them through various methods of user involvement and research.

This paper thus challenges the widespread belief that user involvement is a panacea for bringing technology design closer to the lived realities of older persons. In the interviews that we conducted with the designers, it even remained unclear in how far their sophisticated understanding about localization and domestication were influenced by user involvement in the projects. But what became clear is how their struggle to reconcile a complex understanding of users and use with the complexities of design foregrounded certain representations of older persons while sidelining others. In other words, the specific user representations that came to prevail in both projects, either prosthetic or habilitating, emerged during generification, and not as a result of user research per se.

At a fundamental level, therefore, we argue that user involvement and research needs to be understood as element of a wider generification strategy that is itself scripted, dependent on the used methods and underlying assumptions, and configured by the need to develop solutions that are robust across a variety of local circumstances. Maintaining a sophisticated imagery about users and use across spaces and time in innovation processes appears to be as challenging as creating such an imagery in the first place. Indeed, the last $10-15$ years of involving older persons in design and innovation processes have greatly refined our imagery of older technology users. Insufficient attention to generification strategies, however, might explain why such refined imagery is so seldom reflected in design outcomes (see Peine and Neven, 2011 for this last point). Against this background, our research casts doubt on the effectiveness of claims for yet more user involvement as a response to disappointing technological designs for older persons. Instead, researching and pondering generification strategies more carefully seems to be the more promising route. The conceptual perspective developed in this paper might go a long way in supporting this, and help research and innovation processes to balance the complex realities of designing PHS for the homes of older persons.

More specifically, our research has underpinned how the embedding of PHS in the generic values of contemporary health systems produces a particular risk of downplaying representations of older persons as agents of localization, implementation and innovation. In our case studies, the elements of 'personalization,' 'needs capturing' and 'othering' defined a generification strategy that is marked by an underlying prosthetic logic - a logic in which agency is gradually taken away from older persons, and a sociotechnical agencement is envisioned for the implementation of the robots in which older persons are treated as objects, not as agents. This insight relates generification work with the emerging body of research on 'design paternalism' and 'ageism' in science and technology (see Peine et al., 2014; Peine and Neven, 2011; Joyce and Mamo, 2006;Joyce and Loe, 2010 and the papers of Neven (2015-this issue) and Loe (2015-this issue) in this special issue). Indeed, when older persons are considered as users of health technology, generification work linked to the values of existing health care systems transpires as a pivotal process that pre-figures a division of labor that frames older persons as passive recipients of technology - a key feature of 'ageist design' and 'design paternalism' (see Peine and Neven, 2011; Joyce and Loe, 2010).

In both cases, however, traces of an alternative approach were also present, an approach that we call habilitating generification. These were traces of a generification strategy that envisioned explorative and interactive agency for older persons during the whole innovation process, including implementation and localization. In other words, habilitation saw older persons as agents that would, together with the robots and their social networks, explore and articulate what the emerging role of patient-consumers in aging societies could be, and how technology could help in articulating it further. As such, habilitation acknowledged that a generic value of the robot could not be determined as part of the design process. Rather, a process of 'valueing' (see McLaughlin et al., 1999) would extend well into the sphere of users and use. These traces of habilitation bear the potential to overcome design paternalism and ageist designs. As compared to the prosthetic logic, they grant agency to older technology users in exploring new values, and negotiate the boundaries between health and illness (see Loe, 2014-this issue in this special issue).

Summing up, then, our paper suggests that combining prosthesis and habilitation is a crucial challenge in PHS innovation, and in designing technology for older persons in general. Habilitation is particularly challenging for designers and policy makers. It underlines that, in its move to homes and communities, health technology not only serves specific and pre-defined values. It also highlights that health technology, when merged with other more mundane devices and functionalities, needs to become a playing field for exploring and articulating values that define what it means to be and grow old with technology. As such, habilitation challenges traditional ideas of health technology assessment (HTA) that focus on parameters such as efficacy, quality, safety, ethics or costs. In line with recent claims in the literature (Buxton and Chambers, 2011; Campbell, 2012; Drummond et al., 2013), we thus posit that the nature of value itself, and in particular the process of valuing, deserves a more fine-grained treatment in 
health innovation design and policy. This might ask for broadening existing ideas about 'evidentiality' (Faulkner, 2009) to allow habilitation to enter health technology assessment and innovation policy. For PHS innovation, the existing focus on evidence-based health technology assessment bears the risk of producing innovation processes that follow a prosthetic strategy. Our cases have shown that this might result in innovations that are simply unattractive to older persons, and deprive from them opportunities for meaningful and creative encounters, because prosthesis does not address them as consumers.

Coming to grips with habilitation might thus be the most important challenge for stimulating the dissemination and scaling of available PHS technologies. The research presented in this paper is of course only a first step into this direction. Our results are based on two cases and 8 interviews, and this puts limits on explanatory depth. Especially, our understanding of the elements that mark a prosthetic logic need further exploration in order to capture this logic across a broader range of situations and mechanisms. However, in line with our theory-elaborating approach, the cases explored in this paper illustrate how generification work is an important process that explains the constitution of user representations. Hence, our paper has put generification work on the map of gerontechology innovation. We could demonstrate that the outcome of addressing the localization vs. generification challenge depends on the degrees of agency granted to different actors in different stages of the innovation process. Further research about how habilitation plays out across different locales and phases of PHS innovation is needed to understand this better. The conceptual framework outlined in this paper is tailored to do just that.

\section{Acknowledgements}

The authors thank Laurens Meulenbroek for his contribution to data collection.

\section{References}

Abadie, F., Codagnone, C., van Lieshout, M., Pascu, C., Baum, P., Hoikkanen, A., Valverde, J.A., Maghiros, I., 2011. Strategic intelligence monitor on personal health systems: market structure and innovation dynamics. JRC-IPTS working papers.

Abadie, F., Codagnone, C., van Lieshout, M., Pascu, C., Baum, P., Hoikkanen, A., Valverde, J.A., Maghiros, I., 2011. Strategic intelligence monitor on personal health systems (simphs): Report on typology/segmentation of the PHS market. JRC-IPTS working papers.

Aceros, J.C., Pols, J., Domènech, M., 2015. Where is grandma? Home TeleCare, good aging and the domestication of later life. Technol. Forecast. Soc Change 93, 102-111 (this issue).

Akrich, M., 1995. User representations: practices, methods and sociology. In: Rip, A., Misa, T.J., Schot, J. (Eds.), Managing technology in society: the approach of constructive technology assessment. Pinter Publishers, London, pp. 167-184.

Asveld, L., Michiel, Brom, F.W.A., Dijstelbloem, H., Grinten, T.V.D., Klaassen, P.-J., Teun, 2009. Medische technologie: ook geschikt voor thuisgebruik. Rathenau Instituut, Den Haag.

Barry, A., 2001. Political machines: governing a technological society. Athlone, London.

Blumer, H., 1954. What is wrong with social theory? Am. Sociol. Rev. 19 (1), 3-10 Bowen, G.A., 2006. Grounded theory and sensitizing concepts. Int. J. Qual. Meth. 5 (3), 12-23.

Bryman, A., 2006. Paradigm peace and the implications for quality. Int. J. Soc. Res. Methodol. 9 (2), 111-126.

Buxton, M.J., Chambers, J.D., 2011. What values do the public want their health care systems to use in evaluating technologies? Eur. J. Health Econ. 12 (4) 285-288.
Cabrera, M., Malanowski, N. (Eds.), 2009. Information and communication technologies for active ageing: opportunities and challenges for the European Union. IOS Press, Amsterdam.

Campbell, B., 2012. How to judge the value of innovation. Br. Med. J. 344, e1457.

Callon, M., 2008. Economic markets and the rise of interactive agencements: from prosthetic agencies to habilitated agencies. In: Pinch, T., Swedberg, R. (Eds.), Living in a material world: economic sociology meets science and technology studies. The MIT Press, Cambridge, pp. 29-56.

Cenderello, A., Galasso, G., Gargaro, F., Miele, M., Adames, D.Z., Millard, J., Carpenter, G., Pedersen, K., 2013. Technolage - study on business and financing models related to ICT for ageing well http://ec.europa.eu/digitalagenda/en/news/study-business-and-financing-models-related-ICT-ageingwell.

Codagnone, C., 2009. Reconstructing the whole: present and future of personal health systems. http://www.evia.imasdtic.es/CLI_AETIC/ftpportalweb/ documentos/phs2020-book-rev16082009.pdf (downloaded: 12 June 2013).

Corbin, J., Strauss, A., 2008. Basics of qualitative research - techniques and procedures for developing grounded theory. Sage, Los Angeles.

Dishman, E., 2012. The personal health technology revolution. In: Young, E. (Ed.), Progressions - the third place: health care everywhere. Ernst \& Young, p. 19.

Drummond, M., Tarricone, R., Torbica, A., 2013. Assessing the added value of health technologies: reconciling different perspectives. Value Health 16 (1 Suppl), S7-S13.

Eisenhardt, K.M., Graebner, M.E., 2007. Theory building from cases: opportunities and challenges. Acad. Manage. J. 50 (1), 25-32.

Eisenhardt, K.M., 1989. Building theories from case study research. Acad. Manage. Rev. 14 (4), 532-550.

Faulkner, A., 2009. Medical technology into healthcare and society: a sociology of devices, innovation and governance. Palgrave Macmillan, Basingstoke.

Flandorfer, P., 2012. Population ageing and socially assistive robots for elderly persons: The importance of sociodemographic factors for user acceptance. Int. J. Popul. Res. 2012, 1-13.

Fleck, J., 1993. Configurations: crystallizing contingency. Int. J. Hum. Factors Manuf. 3 (1), 15-36.

Flick, U., 2009. An introduction to qualitative research. Sage Publications, Los Angeles.

Huch, M., 2010. Identification and characterisation of the main stakeholder groups for 'ICT for ageing' solutions., BRAID project. http://www. braidproject.eu/.

Hyysalo, S., 2010. Health technology development and Use: from practicebound imagination to evolving impacts. Routledge, London.

Johannessen, L.K., Ellingsen, G., 2009. Integration and generification - agile software development in the healthcare market. Comput. Supported Coop. Work 18 (5-6), 607-634

Joyce, K., Loe, M., 2010. A sociological approach to ageing, technology and health. Sociol. Health Illn. 32 (2), 171-180.

Joyce, K., Mamo, L., 2006. Graying the cyborg; new directions in feminist analyses of aging, science, and technology. In: Calasanti, T., Slevin, K. (Eds.), Age matters; realigning feminist thinking. Taylor \& Francis Group; Routledge, New York, London.

Kohlbacher, F., Hang, C.C., 2011. Applying the disruptive innovation framework to the silver market. Ageing Intern. 36 (1), 82-101.

Kohlbacher, F., Hang, C.C., 2011. Levering disruptive innovations for the silver market. In: Kohlbacher, F., Herstatt, C. (Eds.), The silver market phenomenon: marketing and innovation in the aging society. Springer, Berlin, pp. 65-77.

Lehoux, P., 2006. The problem of health technology: policy implications for modern health care systems. Routledge, New York.

Loe, M., 2015. Comfort and medical ambivalence in old age. Technol. Forecast. Soc. Change 93, 141-146 (this issue).

López Gómez, D., 2014. Little arrangements that matter. Rethinking autonomyenabling innovations for later life. Technol. Forecast. Soc. Change 93, 91-101 (this issue)

McLaughlin, J., Rosen, P., Skinner, D., Webster, A., 1999. Valuing technology: organisations, culture, and change. Routledge, New York.

Meulenbroek, L., 2011. Innovation \& aging: the image about the elderly user in the smart homes sector. Lambert Academic Publishing, Saarbrücken.

Neven, L., 2015. By any means? Questioning the link between gerontechnological innovation and older people's wish to live at home. Technol. Forecast. Soc. Change 93, 32-43 (this issue).

Neven, L., 2010. But obviously not for me: robots, laboratories and the defiant identity of elder test user. Sociol. Health Illn. 32 (2), 335-347.

Mol, A., Moser, I., Pols, J. (Eds.), 2010. Care in practice - on tinkering in clinics, homes and farms. Transcript, Bielefeld.

Mol, A., Moser, I., Pols, J., 2010. Care: putting theory in practice. In: Mol, A., Moser, I., Pols, J. (Eds.), Care in practice - on tinkering in clinics, homes and farms. Transcript, Bielefeld, pp. 7-19. 
Mort, M., Roberts, C., Milligan, C., 2009. Ageing, technology and the home: a critical project. ALTER - Eur. J. Disabil. Res. 3 (2), 85-89.

Mort, M., Roberts, C., Pols, J., Domenech, M., Moser, I., 2013. Ethical implications of home TeleCare for older people: a framework derived from a multisited participative study. Health Expect. http://dx.doi.org/10.1111/hex.12109.

Mort, M., Roberts, C., Callen, B., 2012. Ageing with TeleCare: care or coercion in austerity? Sociol. Health Illn. 35 (6), 799-812.

Nolte, E., McKee, M., 2008. Caring for people with chronic conditions - a health system perspective. Open University Press, Maidenhead.

Oudshoorn, N., 2011. TeleCare technologies and the transformation of healthcare. Palgrave Macmillan, Basingstoke.

Peine, A., Faulkner, A., Jaeger, B., Moors, E.H.M., 2015. Science, technology and the 'grand challenge' of ageing-Understanding the socio-material constitution of later life. Technol. Forecast. Soc. Change 93, 1-9 (this issue).

Peine, A., Rollwagen, I., Neven, L., 2014. The rise of the "innosumer" - rethinking older technology users. Technol. Forecast. Soc. Change 82, 199-214.

Pritchard, G.W., Brittain, K., 2015. Alarm pendants and the technological Shaping OF older people's care: Between (intentional) help and (irrational) nuisance. Technol. Forecast. Soc. Change 93, 124-132 (this issue).

Peine, A., Neven, L., 2011. Social-structural lag revisited. Gerontechnology 10 (3), 129-139.

Peine, A., Herrmann, A.M., 2012. The sources of use knowledge: towards integrating the dynamics of technology use and design in the articulation of societal challenges. Technol. Forecast. Soc. Change 79 (8), 1495-1512.

Peine, A., 2008. Technological paradigms and complex technical systems - the case of smart homes. Res. Policy 37 (3), 508-529.

Peine, A., 2009. Understanding the dynamics of technological configurations - a conceptual framework and the case of smart homes. Technol. Forecast. Soc. Change 76 (3), 396-409.

Pollock, N., Williams, R., D'Adderio, L., 2007. Global software and its provenance: generification work in the production of organizational software packages. Soc. Stud. Sci. 37 (2), 254-280.

Pollock, N., Williams, R., 2008. Software and organizations - the biography of the enterprise-wide system or how sap conquered the world. Routledge, Abingdon.

Pollock, N., Williams, R., 2010. E-infrastructures: how do we know and understand them? Strategic ethnography and the biography of artefacts. Comput. Supported Coop. Work 19 (6), 521-556.

Pols, J., Willems, D., 2011. Innovation and evaluation: taming and unleashing TeleCare technology. Sociol. Health Illn. 33 (3), 484-498.

Pols, J., Moser, I., 2009. Cold technologies versus warm care? On affective and social relations with and through care technologies. ALTER - Eur. J. Disabil. Res. 3 (2), 159-178.

Roberts, C., Mort, M., 2009. Reshaping what counts as care: older people, work and new technologies. ALTER - Eur. J. Disabil. Res. 3 (2), 138-158.

Romero, N., Sturm, J., Bekker, T., de Linda, V., Kruitwagen, S., 2010. Playful persuasion to support older adults' social and physical activities. Interact. Comput. 22 (6), 485-495.

Sanchez-Criado, T., Lopez, D., Roberts, C., Domenech, M., 2014. Installing TeleCare, installing users: felicity conditions for the instauration of usership. Sci. Technol. Hum. 39 (5), 694-719.

Schartinger, D., Giesecke, S., Heller-Schuh, B., Amanatidou, E., Schreir, G., Miles, I., Pombo-Juárez, L., Saritas, O., Kastner, P., Könnölä, T., 2012. Personal health systems - state of the art. http://www.phsforesight.eu (dowloaded: 13 June 2013).
Schillmeier, M., Domenech, M., 2010. New technologies and emerging spaces of care. Ashgate Publishing, Farnham.

Silverstone, R., Hirsch, E., Morley, D., 1992. Information and communication technologies and the moral economy of the household. In: Silverstone, R. Hirsch, E. (Eds.), Consuming technologies - media and information in domestic spaces. Routledge, London, pp. 15-31.

Stewart, J., Williams, R., 2005. The wrong trousers? beyond the design fallacy: social learning and the user. In: Howcroft, D. (Ed.), Handbook of critical information systems research. Edward Elgar, Cheltenham, pp. 195-221.

Vaughan, D., 1992. Theory elaboration: the heuristics of case analysis. In: Ragin, C.C., Becker, H.S. (Eds.), What is a case? exploring the foundations of social inquiry. Cambridge University Press, Cambridge, pp. 173-202.

Vaughan, D., 2004. Theorizing disaster: analogy, historical ethnography, and the challenger accident. Ethnography 5 (3), 315-347.

Williams, R., Pollock, N., 2012. Moving beyond the single site implementation study: how (and why) we should study the biography of packaged enterprise solutions. Inform. Syst. Res. 23 (1), 1-22.

Willems, D., 2010. Varieties of goodness in high-tech home care. In: Mol, A., Moser, I., Pols, J. (Eds.), Care in practice - on tinkering in clinics, homes and farms. Transcript, Bielefeld, pp. 257-275.

WHO, 2007. Global age-friendly cities: a guide. http://www.who.int/ageing/ age_friendly_cities_guide/en/(download: 12 February 2014).

Zelinski, E.M., Reyes, R., 2009. Cognitive benefits of computer games for older adults. Gerontechnology 8 (4), 220-235.

Dr. Alexander Peine holds a tenured position as Assistant Professor of Science, Technology and Innovation Studies at Utrecht University. Before, he was a Max Weber post-doctoral fellow at the European University Institute (Florence/ Italy), and a Principal Investigator at the Center for Technology and Society at Berlin University of Technology. Alexander's research focuses on two aspects of technological innovations: First, he explores shifting roles of consumers in innovation processes of complex technical systems such as Smart Homes, TeleCare Environments, or Ambient Intelligence. Secondly, he is interested in new technologies that serve the evolving needs of older persons ("Gerontechnology"). He is particularly interested in bridging the fields of innovation studies and social gerontology to explore the "socio-material constitution of later life".

Dr. Ellen Moors is Professor of Sustainable Innovation at Utrecht University. Her research in the field of innovation studies focuses on the dynamics and governance of emerging technologies in science-based sectors, such as agrofood, life sciences and health and ageing. Responsible innovation is an important topic in her work, taking into account societal challenges, values, and welfare issues to ensure more sustainable innovations taking place. The theoretical focus of her work is on the role of user innovations and userproducer interactions in emerging technological innovation systems and changing institutional governance arrangements in emerging technology fields. She teaches courses about management of life sciences innovations and sustainable drug development. Currently she is responsible for the development of a new master program Sustainable Business and Innovation. 